\title{
Engine Torque Simulated Vibration Control for Drive Train Bench System Using Generalized Periodic Disturbance Observer
}

\author{
Yugo Tadano* \\ Senior Member, \\ Takashi Yamaguchi** \\ Member \\ Takao Akiyama** \\ Senior Member, \\ Masakatsu Nomura* \\ Fellow
}

\begin{abstract}
Drive train bench, which is a type of dynamometer, is used to test the power train components of a vehicle such as transmission, torque converter, etc. The test system has to simulate the vibration torque of the engine by motor control. Conventionally, a sine wave is used to simulate the vibration torque of an engine. However, the actual vibration torque waveform contains harmonic distortion components inherent in the engine. Therefore, it is desirable to have a vibration control technique capable of simulating the waveform of the engine torque more accurately. This paper proposes a novel engine torque simulated vibration control for the drive train bench system. The proposed method can achieve a shaft torque detection value that follows the desired engine pulsation torque waveform by utilizing robust resonance suppression control and a generalized periodic disturbance observer. The validity and usefulness of this technology are indicated by the theoretical explanation, simulation, and experimental results.
\end{abstract}

Keywords: generalized periodic disturbance observer, robust resonance suppression control, torque ripple suppression control, engine torque pulse simulation (ETPS)

\section{Introduction}

In order to shorten the development time and to improve the environmental response and performance of vehicles, the motor control technology required by the dynamometer system (vehicle test equipment), is becoming more sophisticated $^{(1)-(6)}$. The virtual drive train evaluation system described in this paper uses the components of the vehicle driving system such as various transmissions and torque converters of automobiles as specimens to measure and verify the power transmission efficiency, endurance etc. The test specimen is connected to a drive motor that replaces the engine, and an absorb motor that absorbs the output. In this system, the vehicle components other than the test specimen can be configured as virtual components on a computer, and the same load as that of driving on a real road can be applied to the test specimen by motor control. In particular, the drive motor that substitutes the engine is required to simulate the vibration torque of the engine. Conventionally, only the fundamental component of the vibration torque is simply generated by a sine-wave vibration control. However, the actual engine torque waveform includes the harmonic distortion components unique to combustion systems. Therefore, in order to conduct a more precise test, a vibration control technique that accurately simulates the shape of the engine torque waveform including the harmonics is desired.

On the other hand, since the transmission system of drive

\footnotetext{
* R\&D Group, MEIDENSHA CORPORATION

515, Kaminakamizo, Higashimakado, Numazu, Shizuoka 4108588, Japan

** Dynamometer Systems Business Unit, MEIDENSHA CORPORATION

127, Nishishinmachi, Ota, Gunma 373-0847, Japan
}

train test equipment shows the characteristics of a multiinertia resonance system comprising of a drive motor, a test specimen and an absorb motor, and the test specimen, which is a torque converter, has the characteristics of a non-linear spring, the resonance frequency, amplitude and phase characteristics change according to the torque. Although drive motors often use low-inertia, high-power Interior Permanent Magnet Synchronous Motor (IPMSM) to achieve high response, due to specifications and structural restrictions, they are susceptible to periodic disturbances such as torque ripples. Therefore, in order to simulate the desired engine vibration waveform in the shaft torque sensor installed on the coupling shaft between the drive motor and the input of the specimen, advanced vibration control technology that reproduces the vibration frequency components while eliminating the influence of the above-mentioned complex mechanical resonance characteristics and disturbances (aperiodic and periodic disturbances) is desired. Further, to fulfil the functions of the engine simulator in various operation modes, it is desirable to have a configuration of the shaft torque feedback control in which the waveform automatically follows the transient changes in the vibration command, rotation speed and torque.

Many prior studies ${ }^{(7)-(15)}$ on resonance suppression control of multi-inertia system, where angular velocity or angle is used as the control quantity have been reported, and are being used in various industrial machinery. On the other hand, since there are only a few cases where the shaft torque required for the vehicle test equipment is used as the controlled variable, even though the shaft torque control methods for engine bench that are used in engine tests have been proposed $^{(16)-(19)}$, no consideration has been given to the vibration control. In the vibration control of drive train bench, cases 
where feed-forward vibration control is performed using the output waveform of the engine model (ETPS: Engine Torque Pulse Simulation) as the command value of the driving motor torque have been reported ${ }^{(3)-(6)}$. However, as seen from the test results of the literature, since it is affected by the torsional resonance of the shaft, noise, and response delay of the highfrequency components due to the test equipment, reproducing the complete engine torque waveform in the shaft torque is considered difficult. Moreover, although there are many descriptions on engine modeling, there has not been enough study/consideration on the simulation of the engine torque waveform with the shaft torque of the drive train test equipment. Therefore, vibration control by shaft torque feedback is being studied ${ }^{(20)}$. In the previous study, the shaft torque vibration control was performed by approximating the system characteristics of the vibration control frequency band of the drive train test system to a three-inertia system, and separating the low-frequency resonance points caused by the non-linear spring characteristics of the test specimen from the high-frequency resonance points caused by the drive motor, shaft torque sensor, coupling stiffness, etc. of the test equipment. Specifically, vibration control by shaft torque feedback is realized by applying I-PD control to the low-frequency steady-state torque control and the $\mu$-design method ${ }^{(21)}$ to the high-frequency resonance suppression control, and combining them. Further, for variable speed operation, it has a mechanism to automatically adjust the amplitude of the vibration waveform. However, this function is limited to the amplitude of the sinusoidal waveform, and automatic adjustment of the engine torque waveform is not considered.

In this paper, we follow the shaft torque feedback control that combines the low-frequency steady state torque control and the high-frequency resonance suppression control, as mentioned in the above prior study ${ }^{(20)}$. On the other hand, instead of the automatic adjustment function of the amplitude of the sinusoidal waveform ${ }^{(20)}$, we propose the engine torque simulated vibration control method ${ }^{(26)}$, which is an improvement of the generalized periodic disturbance observer ${ }^{(22)-(25)}$ proposed by the authors. Since this method has a function to automatically adjust multiple frequency components simultaneously, in addition to realizing the engine torque simulation vibration control including harmonic components, it can also suppress periodic disturbances such as torque ripples. Even if there are changes in the operating conditions (vibration waveform, rotation speed, torque, etc.), the desired waveform can be automatically followed. In other words, it is an arbitrary waveform tracking control method that can generate periodic waveforms as specified by the command value, while comprehensively compensating for the system transfer characteristics such as resonance, attenuation, periodic disturbance, aperiodic disturbance, phase lead/lag, etc. of the system being controlled.

The structure of this paper is as follows: First, we explain the device configuration and the theory of the proposed method. Next, we show the validity and usefulness of the theory from the simulation results for the three-inertia system configuration similar to the previous research ${ }^{(20)}$. Lastly, we prove the feasibility based on experimental results.

\section{System Configuration}

2.1 Drive Train Test System Configuration Figure 1 shows the configuration of the drive train test equipment discussed in this paper. A driving motor and a power absorbing motor are set as the input and output of the specimen torque converter respectively, and a shaft torque sensor is installed between the driving motor and the test specimen. The driving motor performs vibration torque control by shaft torque feedback such that the detected shaft torque value $\tau_{\text {det }}$ becomes the desired torque command value $\tau^{*}$ (engine torque simulated waveform). The power absorbing motor controls the rotation speed $\omega_{m}$ such that it becomes the desired value $\omega_{m}^{*}$ (corresponding to the engine rotation speed).

Figure 2 shows an example of the frequency transfer characteristics from the torque command $\tau_{i n v}^{*}$ of the driving motor side inverter to the detected shaft torque value $\tau_{d e t}$. Examples of physical parameters will be described in the next section. Since the specimen torque converter has non-linear spring characteristics in which the torsional stiffness of the shaft (K23) varies according to the torque, in the example in Fig. 2, the resonance point fluctuation caused by the specimen occurs in the band of about $6[\mathrm{~Hz}]$ to $19[\mathrm{~Hz}]$. Further, since the high-frequency resonance point at about $356[\mathrm{~Hz}]$ occurs due to the moment of inertia of the rotor, shaft torque sensor, couplings etc. of the driving motor and the torsional stiffness of the coupling shaft, it is caused by the test equipment outside the test specimen. Thus, the drive train test equipment has the characteristics of a multi-inertia torsional resonance system.

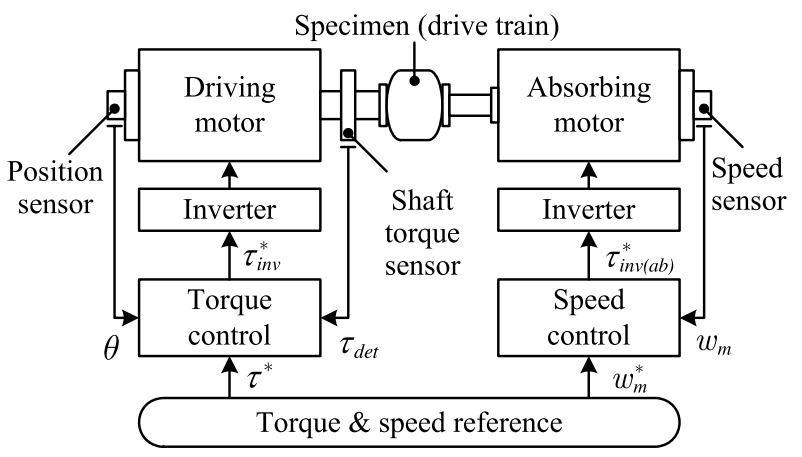

Fig. 1. System configuration of drive train bench

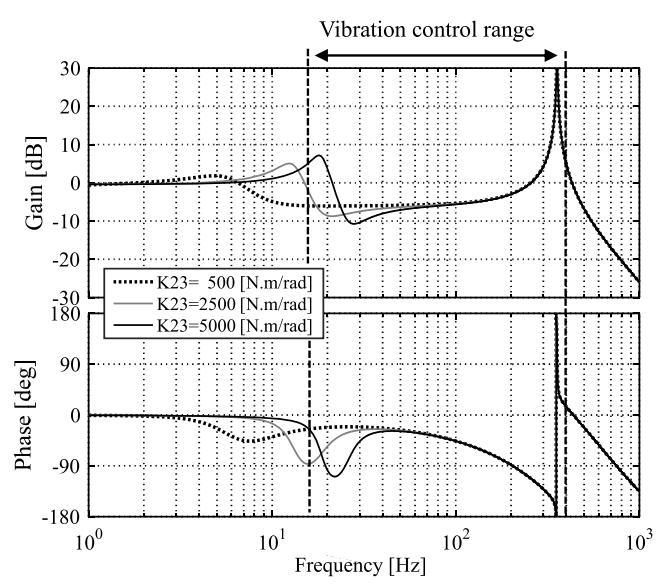

Fig. 2. Bode plot of drive train bench 
Since most commercial vehicles have four-cycle engines where each cylinder combusts the fuel once every two revolutions, large vibrations having a fundamental frequency component of the number of cylinders $\times 0.5 \times$ speed of rotation are generated. When simulating an engine torque of 3 to 8 cylinders for an engine speed of 600 to $6,000\left[\mathrm{~min}^{-1}\right]$, a vibration control band of 15 to $400[\mathrm{~Hz}]$ will be required, as shown in Fig. 2. Further, to simulate the harmonic components of the vibration, it is desirable to be able to control as high a frequency band as possible. However, the frequency control band includes the above-mentioned multi-inertia resonance characteristics. Thus, this becomes an advanced technical task where simultaneous tracking control of the amplitude and phase of multiple vibration frequency components is performed, taking into consideration the attenuation characteristics such as resonance amplification and anti-resonance caused by vibration and periodic disturbance.

2.2 Three-inertia Model As described in the previous section, since a typical drive train testing equipment has two resonance points in the frequency control band, it can be approximated to the transfer function model of three-inertia system $^{(20)}$ shown in Fig. 3. $\tau_{i n v}^{*}$ is the inverter torque command value, $\tau_{d e t}$ is the detected torque value, and $\theta$ is the detected rotational phase value. Table 1 shows the meaning of each parameter and its numerical example. The nonlinearity of the shaft torsional stiffness $K 23$ of the specimen is set to $500[\mathrm{~N} . \mathrm{m} / \mathrm{rad}], 2,500[\mathrm{~N} . \mathrm{m} / \mathrm{rad}]$, and 5,000 [N.m/rad] respectively when the torque value is less than 50 [N.m], 50 to 300 [N.m] and more than 300 [N.m]. $G_{i n v}(s)$ is the inverter torque current response, which is taken as a first-order lag system approximation of cut-off frequency $1[\mathrm{kHz}]$.

$G_{t m}(s)$ is the detection delay of the shaft torque sensor.

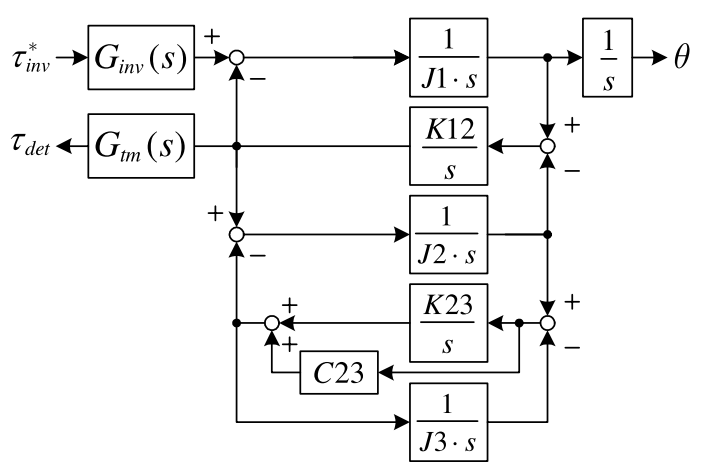

Fig. 3. Block diagram of 3-inertial drive train bench model

Table 1. Parameters of 3-inertial model

\begin{tabular}{|c|c|c|}
\hline$J 1$ & Inertia of drive motor & $0.2\left[\mathrm{~kg} \cdot \mathrm{m}^{2}\right]$ \\
\hline$J 2$ & $\begin{array}{c}\text { Inertia of specimen (drive train) } \\
\text { and coupling shaft }\end{array}$ & $0.2\left[\mathrm{~kg} \cdot \mathrm{m}^{2}\right]$ \\
\hline$J 3$ & Inertia of absorb motor & $4.0\left[\mathrm{~kg} \cdot \mathrm{m}^{2}\right]$ \\
\hline$K 12$ & $\begin{array}{c}\text { Stiffness of coupling shaft } \\
\text { including torque sensor }\end{array}$ & $500,000[\mathrm{~N} \cdot \mathrm{m} / \mathrm{rad}]$ \\
\hline$K 23$ & $\begin{array}{c}\text { Stiffness of specimen (drive train) } \\
\text { with non-linearity }\end{array}$ & $500 \sim 5,000[\mathrm{~N} \cdot \mathrm{m} / \mathrm{rad}]$ \\
\hline$C 23$ & Loss of specimen (drive train) & $10[\mathrm{~N} \cdot \mathrm{m} \cdot \mathrm{s} / \mathrm{rad}]$ \\
\hline$G_{i n v}(s)$ & $\begin{array}{c}\text { Inverter torque response } \\
\text { (1st order lag approximation) }\end{array}$ & cutoff freq. $1[\mathrm{kHz}]$ \\
\hline$G_{t m}(s)$ & $\begin{array}{c}\text { Torque sensor response } \\
\text { (2nd order Pade approximation) }\end{array}$ & dead time 1.1 [ms] \\
\hline
\end{tabular}

From the phase characteristics of the Bode diagram shown in Fig. 2, a second-order Pade approximation with a dead time of 1.1 [ms] was used. It should be noted that the speed control system on the power absorbing motor side in Fig. 1 controls the rotation speed with a response frequency of $1[\mathrm{~Hz}]$, which does not significantly affect the vibration control system.

From the characteristics shown in Fig. 2, the high-band resonance frequency $f_{r H}$ almost coincides with the two-inertial system resonance frequencies $J 1-K 12-J 2$ as shown in Equation (1), and the low-band resonance frequency $f_{r L}$ almost coincides with the two-inertial system resonance frequencies $[J 1+J 2]-K 23-J 3$ as shown in Equation (2). This characteristic is used for the separation of high-frequency band/low-frequency band in the control design described later.

$$
\begin{aligned}
& f_{r H}=\frac{1}{2 \pi} \sqrt{K 12\left(\frac{1}{J 1}+\frac{1}{J 2}\right)}=356[\mathrm{~Hz}] \cdots \cdots \cdots \\
& f_{r L}=\frac{1}{2 \pi} \sqrt{K 23\left(\frac{1}{J 1+J 2}+\frac{1}{J 3}\right)}=6 \sim 19[\mathrm{~Hz}] \cdots \cdots
\end{aligned}
$$

\section{Engine Torque Simulated Vibration Control}

3.1 Overview of the Control Configuration In this paper, we propose an arbitrary waveform tracking control method that generates periodic waveforms according to the command value, while comprehensively compensating for the system transfer characteristics (amplitude characteristics such as resonance and anti-resonance, phase lead/lag, and disturbance). Figure 4 shows the overall control configuration diagram of the driving motor side torque control system. With the three-inertia model (Fig. 3) of the drive train test equipment described in the previous chapter as the control target, resonance suppression control (Fig. 6 described later) is used for the minor loop. Since the frequency transfer characteristics of the system to be controlled containing the minor loop can be generalized by a complex vector expression using the generalized periodic disturbance observer described later, any method can be used for the resonance suppression controller. Here, similar to Reference (20), the $\mu$ design method ${ }^{(21)}$, which is a type of robust control, is used. In the vibration torque controller of the major loop (Fig. 14, described later), an improved method of the generalized periodic disturbance observer is applied to realize the periodic disturbance suppression and engine torque waveform tracking, that were difficult to achieve in Reference (20).

Considering the required performance of the drive train test equipment, it is difficult to configure the shaft torque

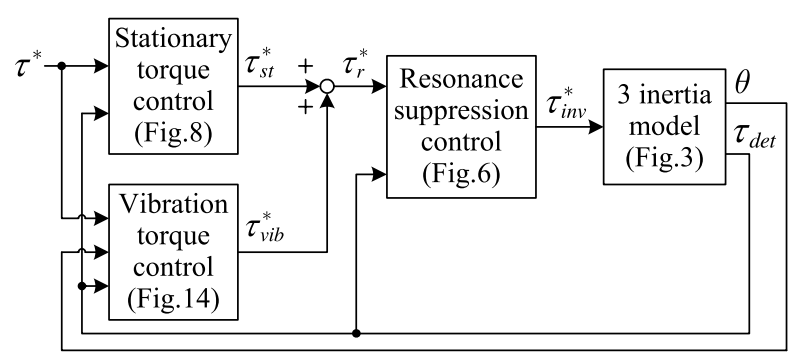

Fig. 4. Overall control configuration diagram 


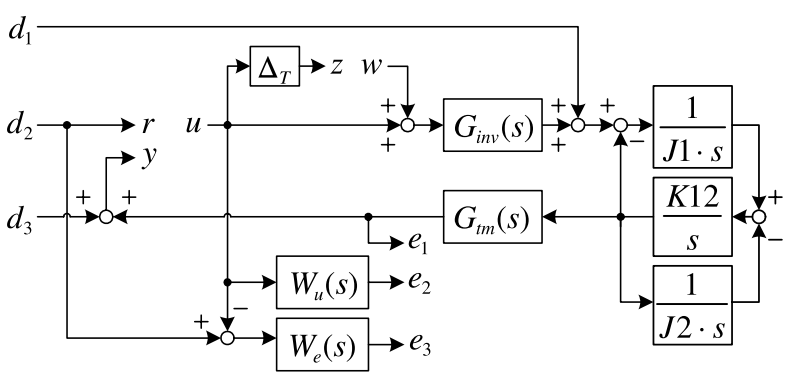

Fig. 5. Generalized plant for high frequency resonance suppression control

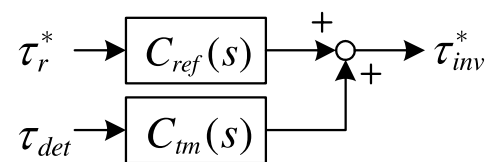

Fig. 6. Resonance suppression controller

feedback covering the entire frequency band of the vibration control with a single controller ${ }^{(20)}$. Therefore, as shown in Equations (1) and (2), focusing on the fact that the low and high band resonance frequencies can be equivalently expressed by their respective two-inertia models, we separately designed the high-frequency resonance suppression control (Fig. 6 described later) and the low-frequency steady-state torque control (Fig. 8 described later), and used a method to superimpose the output $\tau_{v i b}^{*}$ of the vibration torque controller on the output $\tau_{s t}^{*}$ of the steady-state torque controller.

By inputting the superimposed value $\tau_{r}^{*}$ to the highfrequency resonance suppression controller, resonance suppression control, steady-state torque control and vibration torque control are simultaneously achieved.

\subsection{High-frequency Resonance Suppression Control}

The high-frequency resonance point of about $356[\mathrm{~Hz}]$ shown in Fig. 2 almost coincides with the two-inertia system resonance frequencies $f_{r H}$ of $J 1-K 12-J 2$ as shown in Equation (1). In order to separate it from the low-frequency control design using this characteristic, a generalized plant for the equivalent model of the two-inertia system $J 1$ - K12 $J 2$ is constructed as shown in Fig. 5, and the high-frequency resonance suppression controller shown in Fig. 6 is designed using the $\mu$ design method. Table 2 shows the meaning of each symbol in the generalized plant. Usually, the $\mu$-design method that uses the structured singular value $\mu$, takes into account the structured perturbations explicitly to make a robust design. However, when applying it to an actual dynamometer system where various test specimens are replaced and tested, to simplify the operational control design process, rather than performing the parameter identification individually taking the mechanical characteristics as the physical model shown in Fig. 5, system identification is performed by a collective transfer function expression from input to output.

Hence, it is difficult to incorporate the fluctuations of the high-frequency resonance point into the generalized plant as structured perturbations of $K 12$ and $J 2$. Therefore, in this paper, only the inverter torque steady-state error $\Delta_{T}$ is estimated as $\pm 10[\%]$, and the robust stability for the perturbation of mechanical characteristics is confirmed by numerical calculation assuming resonance point fluctuation (maximum
Table 2. Parameters of generalized plant

\begin{tabular}{|c|c|}
\hline$d_{1}$ & Disturbance (including periodic disturbance) \\
\hline$d_{2}, r$ & Input of resonance suppression controller (torque reference) \\
\hline$d_{3}$ & Error of shaft torque detection \\
\hline$u$ & $\begin{array}{l}\text { Output of resonance suppression controller } \\
\text { (inverter torque reference) }\end{array}$ \\
\hline$y$ & Input of resonance suppression controller (shaft torque) \\
\hline$\Delta_{T}$ & Static error of inverter torque \\
\hline$z$ & Controlled output to decrease inverter torque error \\
\hline$w$ & Exogenous input by inverter torque error \\
\hline$e_{1}$ & Evaluation of shaft torque detection \\
\hline$e_{2}$ & Evaluation of inverter torque reference \\
\hline$e_{3}$ & $\begin{array}{c}\text { Evaluation of resonance suppression controller gain in low } \\
\text { frequency range }\end{array}$ \\
\hline$W_{u}(s)$ & $\begin{array}{l}\text { Weighting function to decrease inverter torque in high } \\
\text { frequency range }\end{array}$ \\
\hline$W_{e}(s)$ & $\begin{array}{l}\text { Weighting function to decrease feedback gain of resonance } \\
\text { suppression controller in low frequency range }\end{array}$ \\
\hline
\end{tabular}

$\pm 10[\mathrm{~Hz}])^{(20)}$. The weight functions $W_{u}(s)$ and $W_{e}(s)$ were designed as shown in Equations (3) and (4). Considering the fact that a vibration frequency band of up to $400[\mathrm{~Hz}]$ is required, since $W_{u}(s)$ is for high-frequency noise reduction of the inverter torque input, and $W_{e}(s)$ is for avoiding interference with the low-frequency steady-state torque control, the resonance suppression control feedback gain is set such that it decreases at low-frequencies.

$$
\begin{aligned}
& W_{u}(s)=\frac{s+2 \pi \cdot 400 \cdot 0.01}{0.01 s+2 \pi \cdot 400} \ldots \ldots . \\
& W_{e}(s)=\left(\frac{s+2 \pi \cdot 400}{s+2 \pi \cdot 400 \cdot 0.0001}\right)^{2} \ldots
\end{aligned}
$$

Next, the $\mu$-design is implemented by calculating the generalized plant configured above. Generally, in the $\mu$-design, since it is not possible to directly find a compensator to make the $H_{\infty}$ norm less than 1 , the $D-K$ iteration method, where the compensator $K$ and the scaling matrix $D$ are alternately calculated repeatedly, is used ${ }^{(21)}$. By determining a local approximate optimal solution from this, a compensator having no practical problem is obtained. In this paper, the compensator obtained by three $D-K$ iterations is balanced and truncated, and calculated as the $8^{\text {th }}$ order resonance suppression controller. Equations (5) and (6) show the transfer functions discretized at a control period of $100[\mu \mathrm{s}]$ for the resonance suppression controller calculated by $\mu$-design (Fig. 6). Further, Fig. 7 shows their Bode characteristics. In the controller $C_{r e f}(s)$ for the torque command input $\tau_{r}^{*}$ of the resonance suppression controller, a notch characteristic of about $8[\mathrm{~dB}]$ is obtained near the high-range resonance frequency of $356[\mathrm{~Hz}]$. Further, in the controller $C_{t m}(s)$ for the detected shaft torque value $\tau_{d e t}$, since an effect of feedback gain reduction of $40[\mathrm{~dB} / \mathrm{dec}]$ is obtained in the low-frequency range due to the weight function $W_{e}(s)$, the control spillover with the low-frequency steady-state torque control could be avoided.

3.3 Low-frequency Steady-state Torque Control In addition to being used in the engine torque simulated vibration control dealt in this paper, the drive train test equipment must coexist with the existing control systems for various 


$$
\begin{aligned}
& C_{r e f}\left(z^{-1}\right)=\frac{0.1864-0.5496 z^{-1}+0.2928 z^{-2}+0.6410 z^{-3}-0.8614 z^{-4}+0.1231 z^{-5}+0.3452 z^{-6}-0.2171 z^{-7}+0.03971 z^{-8}}{1-5.296 z^{-1}+12.09 z^{-2}-15.44 z^{-3}+11.90 z^{-4}-5.558 z^{-5}+1.472 z^{-6}-0.1799 z^{-7}+0.003703 z^{-8}}
\end{aligned}
$$

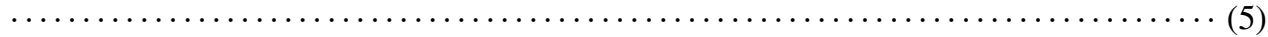

$$
\begin{aligned}
& C_{t m}\left(z^{-1}\right)=\frac{0.06864-0.1938 z^{-1}+0.08408 z^{-2}+0.2415 z^{-3}-0.2842 z^{-4}+0.01998 z^{-5}+0.1199 z^{-6}-0.06770 z^{-7}+0.01153 z^{-8}}{1-5.296 z^{-1}+12.09 z^{-2}-15.44 z^{-3}+11.90 z^{-4}-5.558 z^{-5}+1.472 z^{-6}-0.1799 z^{-7}+0.003703 z^{-8}}
\end{aligned}
$$

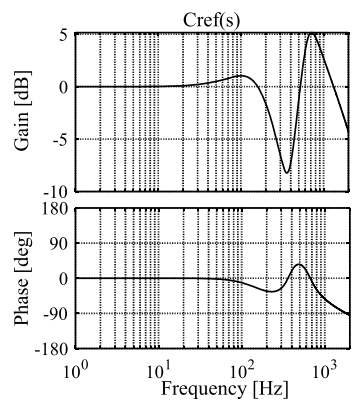

(a) $C_{r e f}(s)$

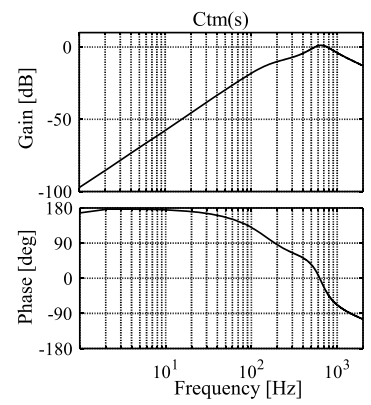

(b) $C_{t m}(s)$
Fig. 7. Bode plot of resonance suppression controller

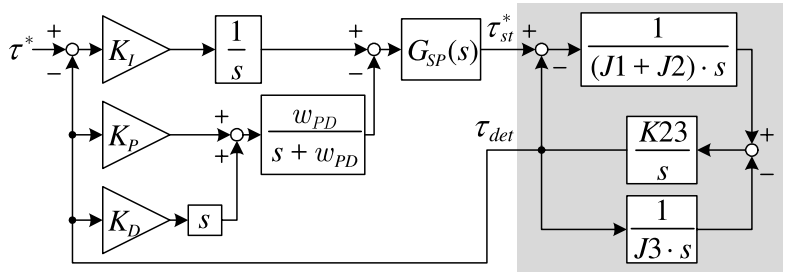

Fig. 8. Stationary torque controller with equivalent 2 inertia model in low frequency range

purposes such as rotational speed control by driving motor, electric inertia control where the moment of inertia of the driving motor is made to look like some other moment of inertia, etc. Further, in addition to the high-frequency resonance suppression control described in the previous section, in the low-frequency range, it is necessary to control the steady-state torque to a desired value, while considering the effect of low-range resonance frequency fluctuation of about 6 to $19[\mathrm{~Hz}]$ shown in Fig. 2, is desired.

In the low-frequency characteristics shown in Fig. 2, although the value seems to be almost $0[\mathrm{~dB}]$ even in uncontrolled state, in reality, it does not become $0[\mathrm{~dB}]$ at $(\mathrm{J} 2+$ $J 3) /(J 1+J 2+J 3)$. Hence, considering the inverter torque error $\Delta_{T}$ and the disturbance of the power absorbing motor, steady-state torque control becomes necessary.

The low-frequency resonance point of about 6 to $19[\mathrm{~Hz}]$ almost coincides with the two-inertia system resonance frequency $f_{r L}$ of $[J 1+J 2]-K 23-J 3$ according to Equation (2). In the control system design of low-frequency region, since the influence of the shaft torque detection dead time $G_{t m}(s)$ and the inverter response $G_{i n v}(s)$ is small, the steady-state torque control is designed excluding these by using the two-inertia equivalent model. In this paper, similar to Reference (20), a proportional differential leading type I-PD controller as shown in Fig. 8 is constructed for the two-inertia system model whose resonance points fluctuate greatly. $G_{S P}(s)$ is a second-order low-pass filter used to avoid the control spillover with the high-frequency resonance suppression controller described in the previous section. Since the highest resonance frequency in the low-frequency range is 19 [Hz], the cutoff frequency is set to $50[\mathrm{~Hz}]$. A first-order low-pass filter of cutoff frequency $w_{P D}[\mathrm{rad} / \mathrm{s}]$ is applied to the PD controller unit. In the low-frequency I-PD control design, since the effect of $G_{S P}(s)$ is negligible, the closed-loop transfer function from $\tau^{*} \rightarrow \tau_{d e t}$ can be approximated by the fourth-order system shown in Equation (7).

$$
\begin{aligned}
\frac{\tau_{d e t}}{\tau^{*}}= & \left(\frac{K 23 K_{I}}{J 1+J 2} s+\frac{K 23 K_{I} w_{P D}}{J 1+J 2}\right) /\left(s^{4}+w_{P D} s^{3}\right. \\
& +\frac{K 23\left(J 1+J 2+J 3+J 3 K_{D} w_{P D}\right)}{(J 1+J 2) J 3} s^{2} \\
& +\frac{K 23\left((J 1+J 2) w_{P D}+J 3\left(K_{I}+w_{P D}+K_{P} w_{P D}\right)\right)}{(J 1+J 2) J 3} s \\
& \left.+\frac{K 23 K_{I} w_{P D}}{J 1+J 2}\right) \ldots \ldots \ldots \ldots \ldots \ldots \ldots \ldots \ldots \ldots
\end{aligned}
$$

Next, the I-PD control parameters are designed such that the closed-loop response of Equation (7) has the desired pole arrangement.

In this paper, we performed coefficient comparison so that the poles in Equation (7) are approximated to the pole arrangement of the fourth-order Butterworth standard form shown in Equation (8), and derived Equation (9).

$$
\begin{aligned}
& \frac{\tau_{d e t}}{\tau^{*}}=\frac{w_{c}^{4}}{s^{4}+a_{3} w_{c} s^{3}+a_{2} w_{c}^{2} s^{2}+a_{1} w_{c}^{3} s+w_{c}^{4}} \\
& \left\{\begin{array}{l}
K_{P}=\frac{J 1+J 2+J 3}{J 3} \cdot\left(\frac{k^{2}\left(a_{1} a_{3}-1\right)}{a_{3}^{2}}-1\right) \\
K_{I}=\frac{J 1+J 2+J 3}{J 3} \cdot \frac{w_{c} k^{2}}{a_{3}} \\
K_{D}=\frac{J 1+J 2+J 3}{J 3} \cdot \frac{a_{2} k^{2}-1}{a_{3} w_{c}} \\
w_{P D}=a_{3} w_{c}
\end{array} .\right.
\end{aligned}
$$

The coefficients of the fourth-order Butterworth standard form are $a_{1}=2.6131, a_{2}=3.4142$, and $a_{3}=2.6131 . k$ is the coefficient of the resonance frequency $f_{r}$, and $w_{c}$ is the response frequency of the standard form, and it is defined as $w_{c}=2 \pi k f_{r}$ in terms of the resonance frequency $f_{r}$. Here, taking $k=1$, and the resonance frequency $f_{r}=6[\mathrm{~Hz}]$, the values detected were, $w_{c}=37.699[\mathrm{rad} / \mathrm{s}], K_{P}=-0.2929, K_{I}$ $=1711.4, K_{D}=0.00082634$, and $w_{P D}=5843.1[\mathrm{rad} / \mathrm{s}]$.

3.4 Verification of the Control Characteristics by Combining the High and Low frequency Regions The resonance suppression control and steady-state torque control designed by separating high and low frequencies are combined as shown in Fig. 4 to realized control over the entire 


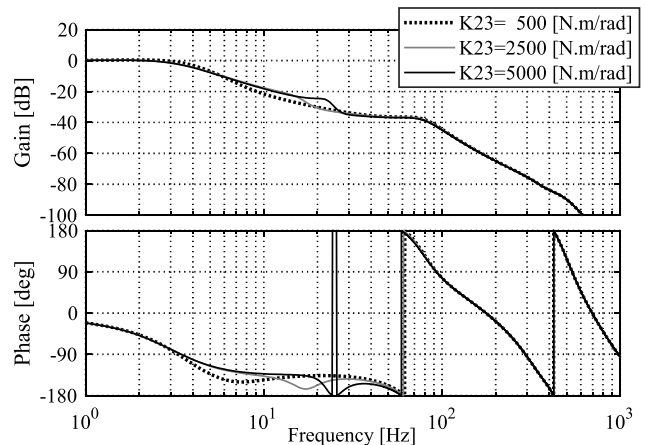

Fig. 9. Bode plot of transfer characteristic $\left(\tau^{*} \rightarrow \tau_{d e t}\right)$

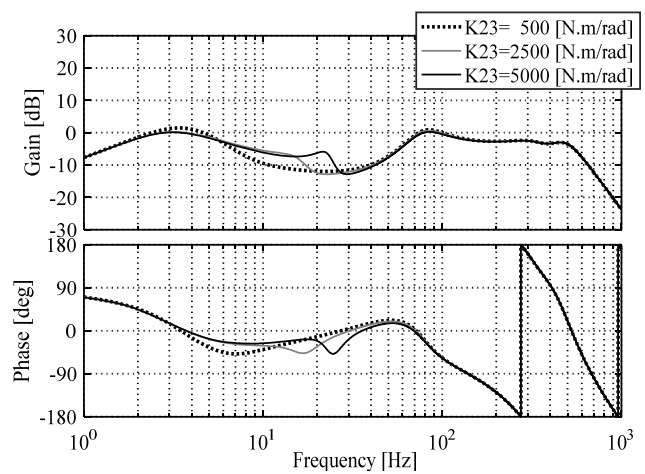

Fig. 10. Bode plot of transfer characteristic $\left(\tau_{r}^{*}\left(\tau_{v i b}^{*}\right) \rightarrow \tau_{d e t}\right)$

frequency band. Figure 9 shows the closed-loop transfer characteristics (command value response) from the torque command value $\tau^{*}$ to the detected shaft torque value $\tau_{d e t}$. As the command value response is about $3[\mathrm{~Hz}]$, tracking control of steady-state torque becomes possible without being affected by the resonance in the high-frequency range or the interference of the resonance suppression control. On the other hand, for example, even if a vibration torque command (vibration frequency band of 15 to $400[\mathrm{~Hz}]$ ) that simulates the engine torque, is simply applied to the torque command $\tau^{*}$, it can be seen that the waveform cannot be reproduced, as the bandwidth is up to about $3[\mathrm{~Hz}]$.

Figure 10 shows the closed-loop transfer characteristics from the input torque $\tau_{r}^{*}$ of the high-frequency resonance suppression controller in Fig. 4 (equivalent to vibration torque controller output $\tau_{v i b}^{*}$, described later,) to the detected shaft torque value $\tau_{d e t}$. Due to the effect of high-frequency resonance suppression control, the high-frequency resonance point of $356[\mathrm{~Hz}]$ in Fig. 2 can be suppressed to less than $0[\mathrm{~dB}]$. Further, since the effect of the $\tau_{\text {det }} \rightarrow \mathrm{I}-\mathrm{PD}$ controller $\rightarrow \tau_{r}^{*}$ loop of the steady-state torque controller is also present, the non-linear resonance point in the low-frequency range of 6 to $19[\mathrm{~Hz}]$ also decreases. However, even if the desired vibration torque command is directly given to $\tau_{v i b}^{*}$ keeping the transfer characteristics of Fig. 10 as it is, since the detected shaft torque value $\tau_{\text {det }}$ does not become the desired value, it is necessary to correct the amplitude and phase characteristics.

Figure 11 shows the closed-loop transfer characteristics (disturbance response) from the disturbance input $d_{1}$ (Fig. 5) to the detected shaft torque value $\tau_{d e t}$. Due to the effect of high-frequency resonance suppression control, although the

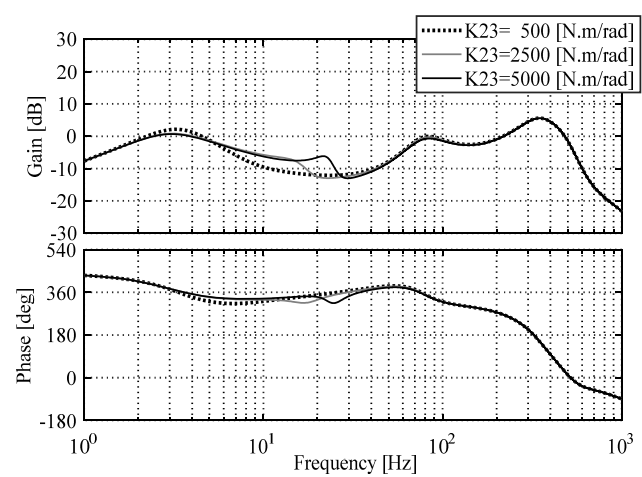

Fig. 11. Bode plot of transfer characteristic $\left(d_{1} \rightarrow \tau_{d e t}\right)$

resonance in the high-frequency of $356[\mathrm{~Hz}]$ is suppressed by about $24[\mathrm{~dB}]$ compared to the uncontrolled state in Fig. 2, a gain of about $5.6[\mathrm{~dB}]$ remains. Thus, for example, if a periodic disturbance such as a torque ripple contained in the disturbance $d_{1}$ is at a rotational speed that matches with this resonance frequency, the effect of resonance becomes remarkable.

From the above characteristics, it is understood that the engine vibration torque cannot be simulated just by combining the low-frequency steady-state torque control and the highfrequency resonance suppression control, and the disturbance suppression performance such as suppression of periodic disturbance etc., is also insufficient. Therefore, in this paper, in addition to the resonance suppression control and the steadystate torque control, we propose a generalized periodic disturbance observer method that controls the vibration torque, while simultaneously suppressing the periodic disturbance, which is the cause for resonance. Thus, we realize a vibration torque control that simulates the engine torque waveform, while comprehensively suppressing resonance, aperiodic disturbance, and periodic disturbance.

3.5 Overview of the Generalized Periodic Disturbance Observer The generalized periodic disturbance observer is a method of extracting the arbitrary frequency component to be controlled and configuring the disturbance observer in the rotational coordinate system synchronized with the frequency component ${ }^{(22)-(25)}$. This section gives an overview of the generalized periodic disturbance observer. First, as a method to extract the frequency components for an arbitrary time waveform $y(t)$, it is converted to the $d$-axis component $Y_{d n}$, and $q_{n}$-axis component $Y_{q n}$, using the orthogonal rotation coordinates $d_{n} q_{n}$ synchronized with the $n^{\text {th }}$ order frequency component defined by Equation (10). $\mathcal{L}$ is the Laplace transform. In this paper, $\theta$ is the motor rotation phase, and the $n^{\text {th }}$ order frequency component is extracted while tracking it according to the change in rotation speed.

$$
\left[\begin{array}{l}
Y_{d n} \\
Y_{q n}
\end{array}\right]=2\left[\begin{array}{l}
G_{F}(s) \\
G_{F}(s)
\end{array}\right] \cdot \mathcal{L}\left\{\left[\begin{array}{c}
\cos n \theta \\
\sin n \theta
\end{array}\right] \cdot y(t)\right\} \cdots \cdots \cdots \cdots
$$

$G_{F}(s)$ is a first-order low-pass filter for the extraction of the frequency component shown in Equation (11). The cutoff frequency is set to $w_{f}=2 \pi \times 3[\mathrm{rad} / \mathrm{s}]$.

$$
G_{F}(s)=\frac{w_{f}}{s+w_{f}} \text {. }
$$

Next, in the orthogonal rotation coordinates $d_{n} q_{n}$, a complex 


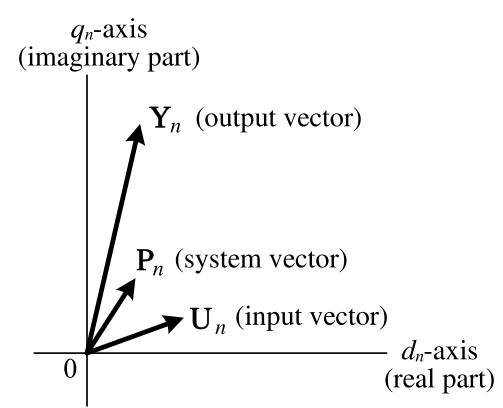

Fig. 12. Definition of rotating coordinate system and complex vector

vector plane with the $d_{n}$-axis component as the real part and $q_{n}$-axis component as the imaginary part is defined as shown in Fig. 12. $\mathbf{P}_{n}$ is the $n^{\text {th }}$-order frequency transfer characteristics vector of the system to be controlled, $\mathbf{U}_{n}$ is the input vector of the $n^{\text {th }}$-order frequency component, and $\mathbf{Y}_{n}$ is the output vector of the $n^{\text {th }}$-order frequency component. They are expressed by Equations (12) to (14) respectively.

$$
\begin{aligned}
& \mathbf{P}_{n}=P_{d n}+j P_{q n} \\
& \mathbf{U}_{n}=U_{d n}+j U_{q n} \\
& \mathbf{Y}_{n}=Y_{d n}+j Y_{q n}
\end{aligned}
$$

Thus, by focusing only on a single frequency component of the orthogonal rotation coordinates $d_{n} q_{n}$, the frequency transfer characteristics of the system can be represented by a onedimensional complex vector. Further, if complex vectors of each frequency component are prepared for the entire control band, tracking during variable speed operation can also be supported. For example, preparing the real part $\hat{P}_{d}\left(f_{n}\right)$ and the imaginary part $\hat{P}_{q}\left(f_{n}\right)$ of the system characteristic table, tabulated at intervals of $1[\mathrm{~Hz}]$ as shown in Equation (15), one set matching the $n^{\text {th }}$-order frequency $f_{n}=n w_{m} / 2 \pi$ of the motor rotation speed $w_{m}$ is sequentially extracted from the table, and applied to the model $\hat{\mathbf{P}}_{n}$ of the real system $\mathbf{P}_{n}$.

$$
\left\{\begin{array}{l}
\hat{P}_{d}\left(f_{n}\right): \hat{P}_{d}(1), \hat{P}_{d}(2), \cdots \hat{P}_{d}\left(f_{\max }\right) \\
\hat{P}_{q}\left(f_{n}\right): \hat{P}_{q}(1), \hat{P}_{q}(2), \cdots \hat{P}_{q}\left(f_{\max }\right)
\end{array}\right.
$$

As described above, even if the system to be controlled is a complex multi-inertia resonance system, it can always be generalized as a simple one-dimensional complex vector on the orthogonal rotation coordinates $d_{n} q_{n}$.

Figure 13 shows the basic configuration of the generalized periodic disturbance observer on the orthogonal rotation coordinates $d_{n} q_{n}$. The vector notation in the diagram denotes a complex vector. The actual system $\mathbf{P}_{n}$ of the $n^{\text {th }}$-order frequency is given by Equation (12), and as described above, it is the $n^{\text {th }}$-order frequency transfer characteristic from the input $\mathbf{U}_{n}$ to the output $\mathbf{Y}_{n}$. The periodic disturbance $\mathbf{D}_{n}$ is taken into consideration in the input section. The basic operation to negate the periodic disturbance $\mathbf{D}_{n}$ follows the method of a conventional disturbance observer. However, the inverse model $\hat{\mathbf{Q}}_{n}$ does not include the differential characteristics, and can be derived simply from the reciprocal of $\hat{\mathbf{P}}_{n}$ as shown in Equation (16). In $\hat{\mathbf{Q}}_{n}$, similar to $\hat{\mathbf{P}}_{n}$, if the real part $\hat{Q}_{d n}$ and the imaginary part $\hat{Q}_{q n}$ are tabulated for each frequency, tracking can be performed for variable speed operation.

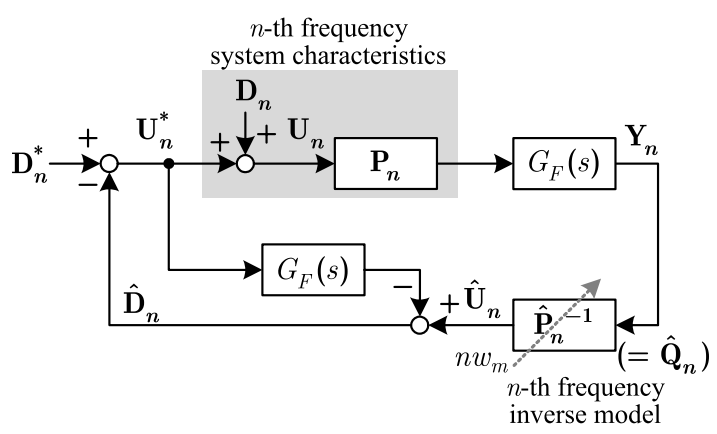

Fig. 13. Basic system configuration of generalized periodic disturbance observer

$$
\begin{aligned}
& \hat{\mathbf{Q}}_{n}=\hat{Q}_{d n}+j \hat{Q}_{q n}=\frac{1}{\hat{P}_{d n}+j \hat{P}_{q n}}=\frac{\hat{P}_{d n}}{\hat{P}_{d n}^{2}+\hat{P}_{q n}^{2}}-j \frac{\hat{P}_{q n}}{\hat{P}_{d n}^{2}+\hat{P}_{q n}^{2}} \\
& \therefore \hat{Q}_{d n}=\frac{\hat{P}_{d n}}{\hat{P}_{d n}^{2}+\hat{P}_{q n}^{2}}, \quad \hat{Q}_{q n}=-\frac{\hat{P}_{q n}}{\hat{P}_{d n}^{2}+\hat{P}_{q n}^{2}} \cdots \cdots(16)
\end{aligned}
$$

The estimated input value $\hat{\mathbf{U}}_{n}$ obtained from the detected value $\mathbf{Y}_{n}$ through $\hat{\mathbf{Q}}_{n}$ is given by Equation (17). By subtracting the input command value $\mathbf{U}_{n}^{*}$ from $\hat{\mathbf{U}}_{n}$ via $G_{F}(s)$, the periodic disturbance estimated value $\hat{\mathbf{D}}_{n}$ is obtained as shown in Equation (18).

$$
\begin{aligned}
& \hat{\mathbf{U}}_{n}=\hat{\mathbf{Q}}_{n} \cdot \mathbf{Y}_{n} \ldots \ldots \ldots \ldots \ldots \ldots \ldots \ldots \ldots \ldots \ldots \ldots \ldots \ldots \ldots \ldots \ldots \ldots \ldots \ldots \ldots \ldots
\end{aligned}
$$

$\mathbf{D}_{n}^{*}$ is the periodic disturbance command value. However, it can be suppressed by making the value 0 . Further, by subtracting $\hat{\mathbf{D}}_{n}$ in Equation (18), periodic disturbance $\mathbf{D}_{n}$ can be cancelled. If vibration is required, the desired value can be entered in $\mathbf{D}_{n}^{*}$.

If this configuration is parallelized, multiple frequency components can be controlled simultaneously, and an arbitrary periodic waveform can be generated by combining them.

Further, for details about the control performance and robustness of the generalized periodic disturbance observer, see References (22) to (25).

3.6 Vibration Torque Control by Generalized Periodic Disturbance Observer In this section, we describe the vibration torque control using the generalized periodic disturbance observer.

As mentioned in Section 2.1, in a four-stroke engine, large vibrations are generated at the number of cylinders $\times 0.5 \times$ rotational frequency, and their harmonics. Taking a fourcylinder four-stroke engine as an example, periodic torque vibrations are generated at even orders like $2^{\text {nd }}, 4^{\text {th }}, 6^{\text {th }}, 8^{\text {th }}$ and so on of the machine speed, and generally the lower order harmonics are larger. On the other hand, periodic disturbances due to the dynamometer equipment such as IPMSM torque ripple $\left(6^{\text {th }}\right.$ order, $12^{\text {th }}$ order, and so on of electrical frequency), inverter current sensor error ( $1^{\text {st }}$ order, $2^{\text {nd }}$ order, and so on of electrical frequency), and dead-time error $\left(6^{\text {th }}\right.$ order etc. of electrical frequency) also occur in a complex manner. In the 4-pole IPMSM used in this paper, periodic disturbances of the $2^{\text {nd }}, 4^{\text {th }}, 12^{\text {th }}$ and $24^{\text {th }}$-order of the machine speed occur.

Based on the periodic characteristics described above, the 


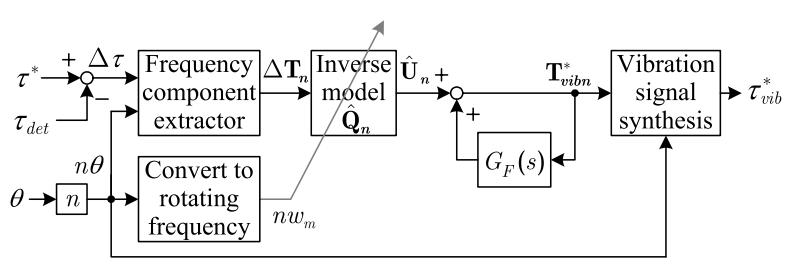

Fig. 14. Vibration torque controller with generalized periodic disturbance observer

purpose of controlling the vibration torque control unit is to follow the desired engine torque for each frequency component, while eliminating the above periodic disturbances.

Figure 14 shows the configuration diagram where the vibration torque control unit of Fig. 4 is expanded. First, the deviation $\Delta \tau$ between the torque command value $\tau^{*}$ and the detected torque value $\tau_{\text {det }}$ is taken, and the periodic disturbance observer is configured such that the $n^{\text {th }}$-order frequency component $\Delta \mathbf{T}_{n}$ of the torque deviation included in $\Delta \tau$ is set to 0 . Here, $\Delta \mathbf{T}_{n}\left(=\Delta T_{d n}+j \Delta T_{q n}\right)$ is extracted from Equation (19) using the $d_{n} q_{n}$ orthogonal rotation coordinate transformation.

$$
\left[\begin{array}{l}
\Delta T_{d n} \\
\Delta T_{q n}
\end{array}\right]=2\left[\begin{array}{l}
G_{F}(s) \\
G_{F}(s)
\end{array}\right] \cdot \mathcal{L}\left\{\left[\begin{array}{c}
\cos n \theta \\
\sin n \theta
\end{array}\right] \cdot \Delta \tau(t)\right\} \cdots \cdots \cdots
$$

In this paper, considering the $2^{\text {nd }}, 4^{\text {th }}, 6^{\text {th }}$ and $8^{\text {th }}$ order vibrations of a four-cylinder engine, and the $2^{\text {nd }}, 4^{\text {th }}, 12^{\text {th }}$, and the $24^{\text {th }}$-order periodic disturbances, and by setting the orders of $N=[2,4,6,8,12,24]$ for $n$, each frequency component $\Delta \mathbf{T}_{n}$ is extracted in parallel.

Next, the extracted $\Delta \mathbf{T}_{n}$ is multiplied by the inverse model $\hat{\mathbf{Q}}_{n}$. As shown in Equations (15) and (16) of the previous section, in $\hat{\mathbf{Q}}_{n}$, the real part $\hat{Q}_{d n}$ and the imaginary part $\hat{Q}_{q n}$ are tabulated in $1[\mathrm{~Hz}]$ increments, and the values synchronizing with $f_{n}=n w_{m} / 2 \pi$ are used for each order. Here, we describe the method of setting the table for the inverse model $\hat{\mathbf{Q}}_{n}$. The control target system when viewed from the vibration torque control unit $\tau_{v i b}^{*}$ of Fig. 4 has the closed-loop transfer characteristic $\tau_{v i b}^{*} \rightarrow \tau_{d e t}$ (Fig. 10). Figure 10 is the bode diagram of the minor loop that includes $\tau_{d e t} \rightarrow$ I-PD controller $\rightarrow \tau_{r}^{*}$ of the high-frequency resonance suppression control and the steady-state torque controller. Converting this amplitude and phase characteristics (polar form) into a complex vector (real part $\hat{P}_{d}\left(f_{n}\right)$, and imaginary part $\left.\hat{P}_{q}\left(f_{n}\right)\right)$ in steps of $1[\mathrm{~Hz}]$, and calculating its inverse characteristics (real part $\hat{Q}_{d}\left(f_{n}\right)$, and imaginary part $\left.\hat{Q}_{q}\left(f_{n}\right)\right)$ by Equation (16), we tabulate the inverse model $\hat{\mathbf{Q}}_{n}$ as shown in Equation (20).

$$
\left\{\begin{array}{l}
\hat{Q}_{d}\left(f_{n}\right): \hat{Q}_{d}(1), \hat{Q}_{d}(2), \cdots, \hat{Q}_{d}\left(f_{\max }\right) \\
\hat{Q}_{q}\left(f_{n}\right): \hat{Q}_{q}(1), \hat{Q}_{q}(2), \cdots, \hat{Q}_{q}\left(f_{\max }\right)
\end{array}\right.
$$

The output through the inverse model $\hat{\mathbf{Q}}_{n}$ is given by $\hat{\mathbf{U}}_{n}$. Since our aim is to set the frequency component $\Delta \mathbf{T}_{n}$ of the torque deviation $\Delta \tau$ to $0, \mathbf{D}_{n}^{*}$ in Fig. 13 becomes 0 . When the control block $\hat{\mathbf{U}}_{n} \rightarrow \mathbf{U}_{n}^{*}$ is transformed, it can be simplified by the positive feedback method via $G_{F}(s)$ as shown by $\hat{\mathbf{U}}_{n} \rightarrow \mathbf{T}_{v i b n}^{*}$ in Fig. 14. By inversely transforming $\mathbf{T}_{v i b n}^{*}$ ( = $T_{v i b d n}^{*}+j T_{v i b q n}^{*}$ ) into the time domain by Equation (21), and combining the waveform of each order set by $N$, the output $\tau_{v i b}^{*}$ of the vibration torque control unit is obtained.

$$
\tau_{v i b}^{*}(t)=\sum_{n=N(1)}^{N(k)}\left(T_{v i b d n}^{*} \cos n \theta+T_{v i b q n}^{*} \sin n \theta\right) \cdots \cdots
$$

As described above, tracking of engine torque waveform that has periodicity and suppression of periodic disturbance are realized simultaneously for each frequency component.

\section{Simulation Verification}

Using the characteristics and parameters of the threeinertia system of Chapter 2, the validity and effectiveness of the proposed engine torque simulated vibration control method are verified by numerical simulation. It should be noted that, here, the low-frequency steady-state torque control (I-PD control), the high-frequency resonance suppression control, and the generalized periodic disturbance observer are abbreviated as I-PD, RSC, and GPDO respectively.

First, the engine torque simulation performance of the shaft torque is verified in a steady operation state. The vibration torque waveform of the 4-cylinder engine model is used for the torque command value $\tau^{*}$, and its average torque is set to 100 [N.m]. As a periodic disturbance, 1[\%], 1[\%], 3[\%], and $3[\%]$ respectively of the $2^{\text {nd }}, 4^{\text {th }}, 12^{\text {th }}$, and $24^{\text {th }}$-order periodic disturbance described in Section 3.6 is applied, and as an aperiodic disturbance, Gaussian white noise of standard normal distribution is applied to the inverter torque section and the shaft torque sensor detection section. Further, the effect of the inverter torque error $\Delta T$ is also taken into consideration by assuming it to be $-10[\%]$. The rotation speed is set to $1,780\left[\mathrm{~min}^{-1}\right]$ so that the $12^{\text {th }}$-order periodic disturbance matches with the high-band resonance frequency $f_{r H}=$ $356[\mathrm{~Hz}]$, and the detected shaft torque value $\tau_{\text {det }}$ is compared and verified under strict conditions where the shaft torsional resonance occurs.

Figure 15 shows the results when the vibration torque command was directly applied to the test specimen having the characteristics of Fig. 2 in feed-forward (I-PD: OFF, RSC: OFF, GPDO: OFF). As there is no RSC/GPDO, a large torsional resonance occurs due to the $12^{\text {th }}$-order of the periodic disturbance. Further, since there is no I-PD, average torque is reduced to 90 [N.m] due to the effect of the inverter torque error. Figure 16 shows the results when only the RSC was used to suppress resonance (I-PD: OFF, RSC: ON, GPDO: OFF). From the results of resonance suppression control, it can be seen that although the resonance due to the $12^{\text {th }}$-order periodic disturbance is attenuated, the engine torque waveform could not be followed. Further, the average torque also dropped to 90 [N.m] due to the absence of I-PD. Figure 17

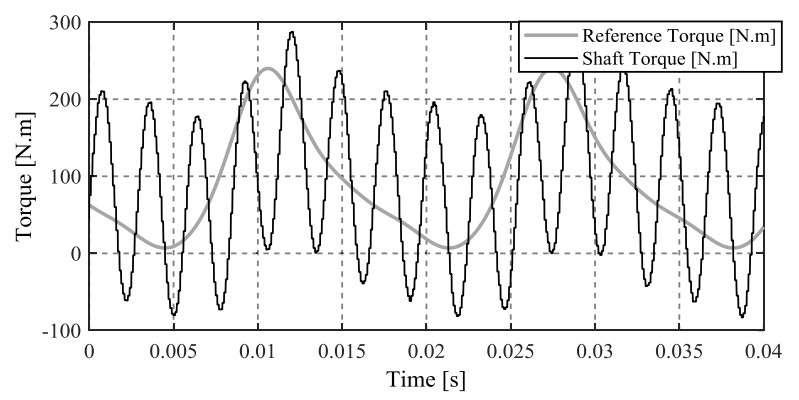

Fig. 15. Simulation result under the condition of I-PD: OFF, RSC: OFF, GPDO: OFF 


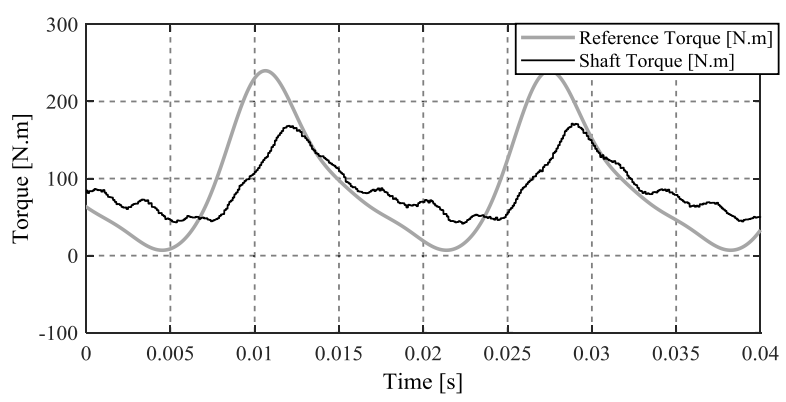

Fig. 16. Simulation result under the condition of I-PD: OFF, RSC: ON, GPDO: OFF

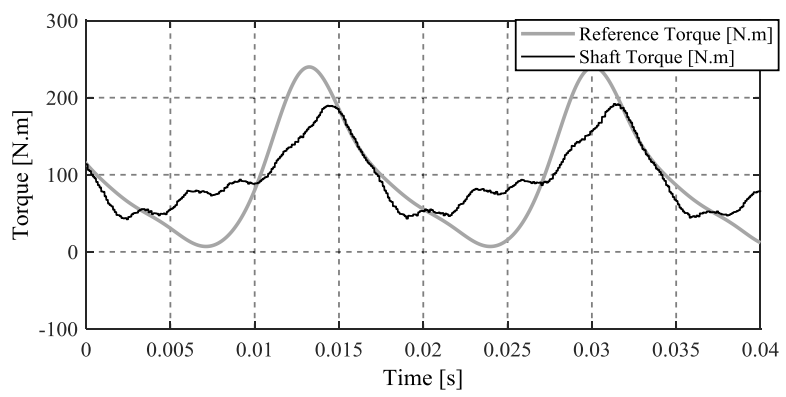

Fig. 17. Simulation result under the condition of I-PD: ON, RSC: ON, GPDO: OFF

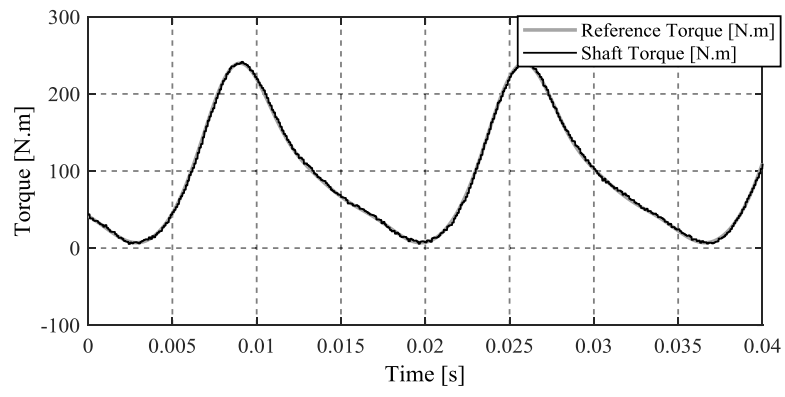

Fig. 18. Simulation result under the condition of I-PD: ON, RSC: ON, GPDO: ON (proposed method)

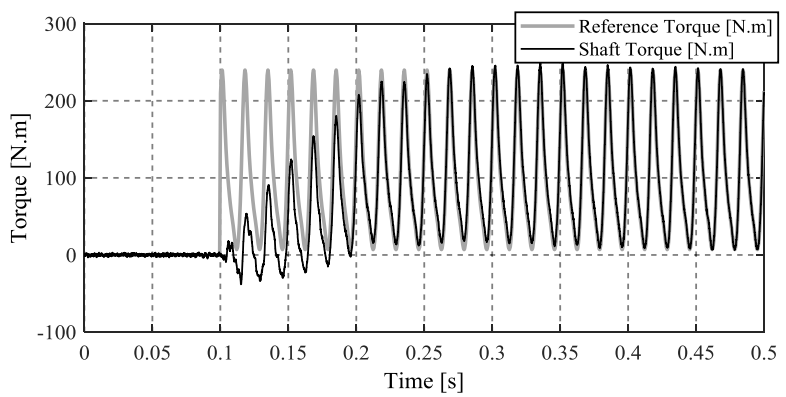

Fig. 19. Simulation result of torque step response with proposed method

shows the results when I-PD was added to RSC, and the vibration torque command was given to $\tau_{v i b}^{*}$ by feed-forward (I-PD:ON, RSC: ON, GPDO: OFF). By the effect of I-PD, although the average torque could be suppressed to 100 [N.m], the engine torque waveform could not be followed. Figure 18 shows the results of the proposed method of using the generalized periodic disturbance observer (I-PD: ON, RSC: ON, GPDO: ON). The engine torque waveform could be successfully simulated while comprehensively suppressing the periodic disturbances, aperiodic disturbances, and resonance).
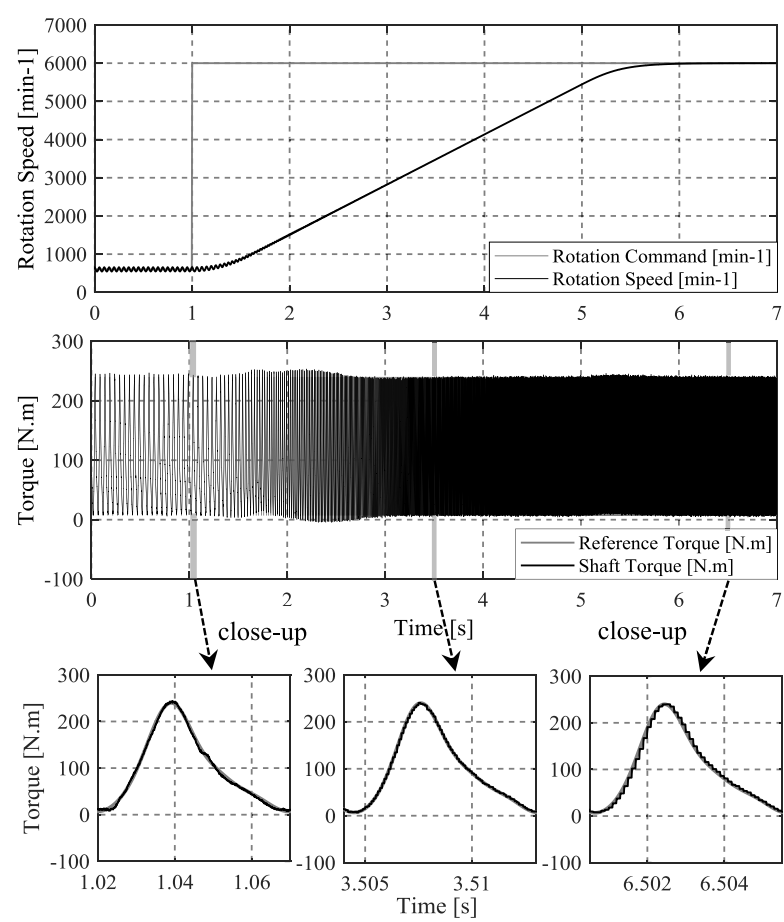

Fig. 20. Simulation result of transient response during rotation speed acceleration with proposed method

Next, we verify the transient control characteristics with respect to the changes in torque and rotational speed, with the proposed method. Figure 19 shows the results when the average torque is changed in steps from $0 \rightarrow 100$ [N.m], and the vibration torque amplitude is changed in steps from $0 \rightarrow 100$ [N.m], at a rotational speed of $1,780\left[\mathrm{~min}^{-1}\right]$. The engine torque waveform could be tracked in approximately 0.3 seconds after the step change, confirming that there is no problem in the torque transient response.

Figure 20 shows the results when the rotational speed was changed from $600 \rightarrow 6,000\left[\mathrm{~min}^{-1}\right]$, while maintaining an engine torque waveform of average torque 100 [N.m] and vibration torque amplitude 100 [N.m]. Since the vibration frequency increases while simulating the engine torque waveform, it is confirmed that it could follow the changes in the rotational speed.

\section{Experimental Verification}

The feasibility of the proposed method is verified with an opposing-type motor test equipment. In this paper, for the convenience of experimental system construction and posting of data, the experiment was performed in a two-inertia system with a resonance frequency of about 317 [Hz], without including the characteristics of the low-frequency drive train test specimen. Table 3 shows the main parameters of the experimental system. Although the low-frequency resonance did not occur, similar to the simulation, the control system testing was performed by combining the lowfrequency steady-state torque control (I-PD control), highfrequency resonance suppression control ( $\mu$-design), and vibration torque control using the generalized periodic disturbance observer.

Figure 21 the experimental results when a 4-cylinder engine torque waveform of average torque of 2 [N.m] and 
Table 3. Experimental system parameters

\begin{tabular}{|c|c|}
\hline Equivalent inertia of drive motor & $0.0073\left[\mathrm{~kg} \cdot \mathrm{m}^{2}\right]$ \\
\hline Equivalent inertia of absorb motor & $0.0229\left[\mathrm{~kg} \cdot \mathrm{m}^{2}\right]$ \\
\hline Equivalent stiffness of coupling shaft & $22,000[\mathrm{~N} \cdot \mathrm{m} / \mathrm{rad}]$ \\
\hline Motor rated power & $1.5[\mathrm{~kW}]$ \\
\hline Motor basic rotation speed & $1,500\left[\mathrm{~min}^{-1}\right]$ \\
\hline Number of poles & 8 \\
\hline Control period & $100[\mu \mathrm{s}]$ \\
\hline
\end{tabular}

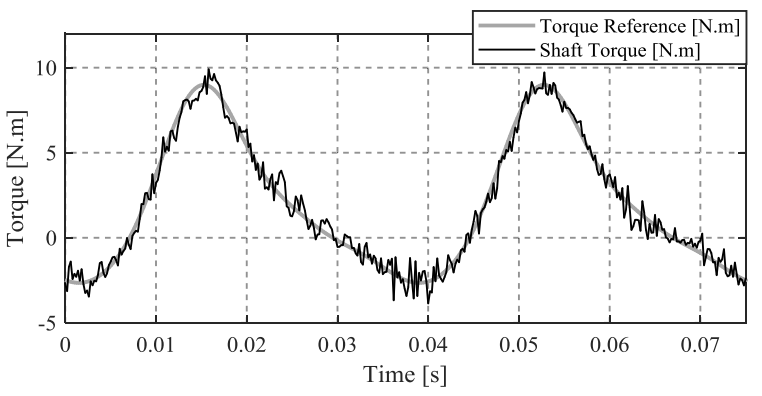

Fig. 21. Experimental result under the condition of IPD: ON, RSC: ON, GPDO: ON ( $=[2,4,6,8,24$, 48])

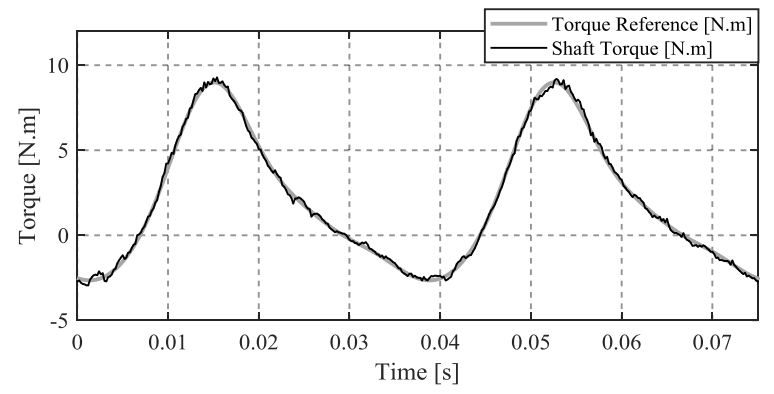

Fig. 22. Experimental result under the condition of IPD: ON, RSC: ON, GPDO: ON (N = [2, 4, 6, 8, 10, 12, $14,16,18,20,22,24,26,46,48,50])$

vibration torque amplitude of 5 [N.m] was applied with a rotation speed of $800\left[\mathrm{~min}^{-1}\right]$, where the $24^{\text {th }}$-order periodic disturbance $\left(6^{\text {th }}\right.$-order electrical frequency $\times 4$ pairs of poles) due to torque ripple almost coincided with the resonance frequency. Taking into consideration the lower-order components of the engine torque waveform such as $2^{\text {nd }}, 4^{\text {th }}, 6^{\text {th }}$, and $8^{\text {th }}$-order components, and $24^{\text {th }}$ and $48^{\text {th }}$-order periodic disturbances, the control target order of GPDO was set to $N=$ $[2,4,6,8,24,48]$. In general, although a shaft torque waveform that follows the waveform of the command value is obtained, it can be seen that the other order components that are not considered as control targets remain as disturbances. Since the actual IPMSMs and inverters have non-linearity, it is considered that sidebands and mutual interference due to periodic disturbances and frequency components of the vibration torque occur in a complex manner. Therefore, the order of the control target of the GPDO is expanded to $N=$ $[2,4,6,8,10,12,14,16,18,20,22,24,26,46,48,50]$, and the experimental results are shown in Fig. 22. By increasing the order of the target, the disturbance was sufficiently eliminated, and a good shaft torque waveform similar to the simulation result was obtained.

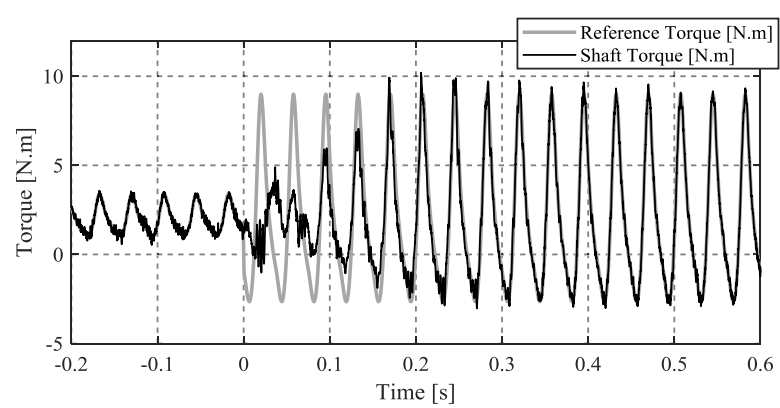

Fig. 23. Experimental result of torque step response with proposed method

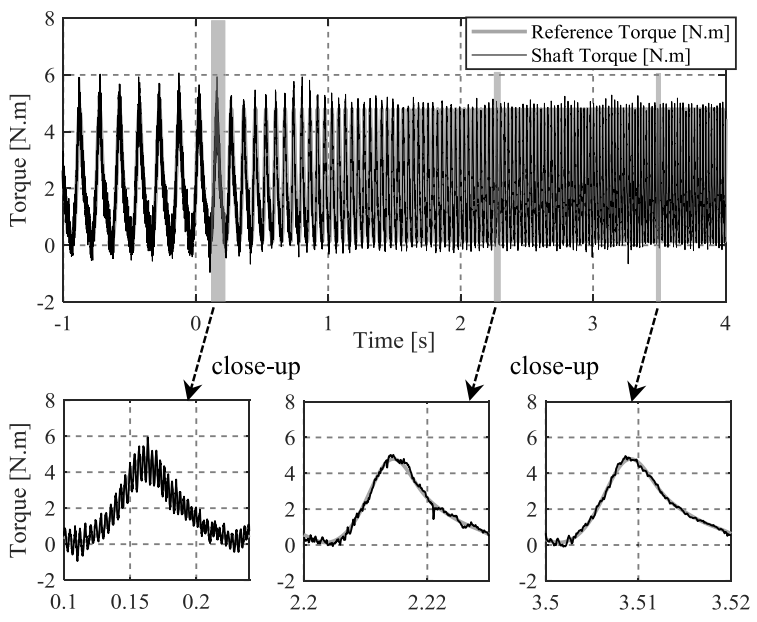

Fig. 24. Experimental result of transient response during rotation speed acceleration with proposed method

Figure 23 shows the experimental results when the vibration amplitude was changed in steps from $1 \rightarrow 5$ [N.m] while simulating the engine torque waveform, at a rotation speed of $800\left[\mathrm{~min}^{-1}\right]$. It was confirmed that the vibration torque amplitude could follow in about 0.2 seconds. Figure 24 shows the experimental results when the rotation speed was accelerated from $200 \rightarrow 1,400\left[\mathrm{~min}^{-1}\right]$ in about 3.5 seconds while keeping the vibration amplitude of the engine torque waveform constant. The possibility of following the change in vibration frequency while maintaining the engine torque waveform could be confirmed.

\section{Conclusion}

In this paper, we have proposed an engine torque simulated vibration control method using a generalized periodic disturbance observer, and verified its validity and usefulness. From the simulation and experimental results, we have elucidated that it is possible to realize the tracking and simulation of engine torque waveform, while simultaneously suppressing the resonance, aperiodic disturbance and periodic disturbance of the drive train test system, which was difficult in the conventional method. Further, since the generalized periodic disturbance observer is a simple algorithm and the reproducibility of the waveform can be improved by increasing the number of orders parallelized, it is considered that it can support complex drive train tests such as engine misfire mode etc. We plan to continue examining the items required for the specimen test.

In this paper, we have applied the robust resonance 
suppression control by $\mu$-design method to the minor loop of the generalized periodic disturbance observer for drive train test system. However, other methods are also feasible. Further, in the feedback control, the shaft torque can also be replaced with other physical quantities (such as current, voltage or rotation speed). In other words, since it can be used to suppress vibrations in various systems and track arbitrary repetitive waveforms, we intend to continue expanding its applications.

\section{References}

(1) M. Amari, K. Kawakubo, and T. Shimizu: "Large-Capacity Drivetrain Test System with Torque Oscillation Function", MEIDEN REVIEW, Vol.157, No.1, pp.29-31 (2013)

( 2 ) K. Ogawa, K. Kawakubo, and T. Shimizu: "Drive Motor Simulating Engine Torque Fluctuation”, MEIDEN REVIEW, Vol.170, No.2, pp.19-21 (2017)

( 3 ) Y. Igarashi, K. Kondo, H. Kobayashi, and S. Sunaga: "Development of Control Application for Automobile Test Bench System", TOYO DENKI Review, Vol.132, pp.6-9 (2015) (in Japanese)

( 4 ) N. Newberger and B. Johnson: "Testing Electrified Drivetrains for Vehicles without the Battery or Engine", HORIBA Technical Reports, No.42, pp.5666 (2014)

( 5 ) ABB: "High-end drive technology Engine Torque Pulse Simulation", ABB brochure (2013)

( 6 ) R. Ahlawat, S. Jiang, D. Medonza, J. Kitchen, and M.H. Smith: "Engine torque pulse and wheel slip emulation for transmission-in-the-loop experiments", 2010 IEEE/ASME International Conference on Advanced Intelligent Mechatronics, pp.688-695 (2010)

( 7 ) Y. Hori: "2-Mass System Control based on Load-Side Acceleration Control and State Feedback", IEEJ Trans. IA, Vol.112, No.5, pp.499-500 (1992) (in Japanese)

( 8 ) S. Morimoto, M. Sugimoto, Y. Takeda, and T. Hirasa: "Vibration Suppression and Pole Assignment of Two-Mass System by State Feedback Control", IEEJ Trans. EIS, Vol.113, No.10, pp.781-788 (1993) (in Japanese)

( 9 ) K. Yuki, T. Murakami, and K. Ohnishi: "Vibration Control of a 2 Mass Resonant System by the Resonance Ratio Control", IEEJ Trans. IA, Vol.113, No.10, pp.1162-1169 (1993) (in Japanese)

(10) M. Hirata, L.Z. Liu, and T. Mita: "Active Vibration Control of a 2-mass Spring System using $\mu$-Synthesis", IEEJ Trans. IA, Vol.114, No.5, pp.512519 (1994) (in Japanese)

(11) T. Yamada, Y. Yamamoto, and T. Ashikaga: "Vibration Suppression Control of 2 Mass Resonant System using Inertia Control Method", IEEJ Trans. IA, Vol.114, No.10, pp.1053-1054 (1994) (in Japanese)

(12) Y. Hori: "Control of 2-Inertia System only by a PID Controller", IEEJ Trans. IA, Vol.115, No.1, pp.86-87 (1995) (in Japanese)

(13) H. Kobayashi, Y. Nakayama, and K. Fujikawa: "Speed Control of MultiInertia System only by a PID Controller", IEEJ Trans. IA, Vol.122, No.3, pp.260-265 (2002) (in Japanese)

(14) S. Katsura and K. Ohnishi: "Vibration Control of Multi-Mass Resonant System Based on Phase-Load Compensator", IEEJ Trans. IA, Vol.126, No.12, pp.1601-1607 (2006) (in Japanese)

(15) S. Hara, Y. Chida, M. Saeki, and K. Nonami: "Benchmark Problem for Robust Control. (I). Position and Velocity Control for Coupled Three-Inertia System", Journal of the Society of Instrument and Control Engineers, Vol.34, No.5, pp.403-409 (1995) (in Japanese)

(16) K. Shirota, F. Baba, M. Horikoshi, and K. Sato: “"Virtual dynamic load" testing system for engine", JSAE, No.66-00, pp.1-4 (2000) (in Japanese)

(17) K. Kimishima and H. Nishimura: "Robust Control of Engine Test Bed for Vehicle Motion Simulation”, T. JSME Series C, Vol.67, No.653, pp.94-101 (2001) (in Japanese)

(18) T. Akiyama, M. Kobayashi, Y. Sawada, and M. Nomura: "Control of Standard Engine Test Bench System for Dynamic Road Load Tests”, SICEICASE International Joint Conference 2006, pp.1566-1569 (2006)

(19) S. Shimonomura, K.Z. Liu, T. Akiyama, Y. Tadano, and M. Nomura: "A Passivity Based Robust Design Method for the Control of Engine Benches", The 35th Chinese Control Conference (CCC2016), pp.8885-8888 (2016)

(20) T. Akiyama, K. Ogawa, Y. Sawada, and T. Yamamoto: "Shaft Torque Vibration Control of Drive-Train Bench", IEEJ Trans. EIS, Vol.134, No.7, pp.909916 (2014) (in Japanese)
(21) K. Nonami, H. Nishimura, and M. Hirata: "Control System Design by MATLAB", Tokyo Denki University Press (1998) (in Japanese)

(22) Y. Tadano, T. Akiyama, M. Nomura, and M. Ishida: "Periodic Learning Suppression Control of Torque Ripple Utilizing System Identification for Permanent Magnet Synchronous Motors", IEEE International Power Electronics Conference 2010 (IPEC-Sapporo), pp.1363-1370 (2010)

(23) Y. Tadano, T. Akiyama, M. Nomura, and M. Ishida: "Torque Ripple Suppression Control Based on the Periodic Disturbance Observer with a Complex Vector Representation for Permanent Magnet Synchronous Motors", IEEJ Trans. IA, Vol.132, No.1, pp.84-93 (2012) (in Japanese)

(24) T. Yamaguchi, Y. Tadano, and N. Hoshi: "Torque Ripple Suppression Control by Periodic Disturbance Observer with Model Error Correction", IEEJ Trans. IA, Vol.134, No.2, pp.185-192 (2014) (in Japanese)

(25) Y. Tadano, K. Oi, and T. Yamaguchi: "Generalized Periodic Disturbance Observer Technology with Automatic Learning Functions", MEIDEN REVIEW, Vol.166, No.1, pp.33-41 (2016)

(26) Y. Tadano, T. Yamaguchi, T. Akiyama, and M. Nomura: "A vibration control technique which simulated an engine torque for drive train bench test", The papers of Technical Meeting on Motor Drive, IEE Japan, MD-16-070, pp.93-98 (2016) (in Japanese)

Yugo Tadano (Senior Member) received the M.E. degree from Mie

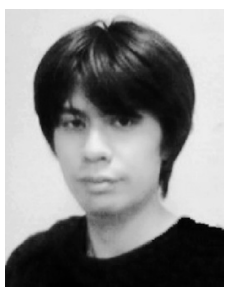
University, Japan, in 2002. In 2002, he joined MEIDENSHA CORPORATION. He currently belongs to the Basic \& Core Technology Research Laboratories, $R \& D$ Group. He is engaged in research and development on power electronics and measurement control technology. In 2006, he received an IEE Japan Best Paper Presentation Award.

Takashi Yamaguchi (Member) received the M.E. degree from Seikei

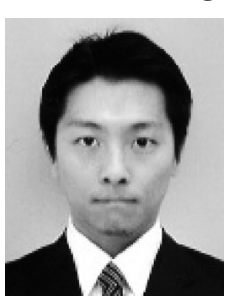
University, Japan, in 2006. In 2006, he joined MEIDENSHA CORPORATION. He currently belongs to the Dynamometer Systems Business Unit. He is engaged in research and development on automotive power measurement systems and measurement control technology. In 2015, he received Ph.D. degree from Tokyo University of Science.

Takao Akiyama (Senior Member) received the M.E. degree from Os-

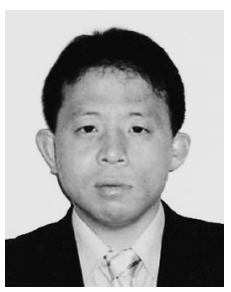
ka University, Japan, in 1994. In 1994, he joined MEIDENSHA CORPORATION. He currently belongs to the Dynamometer Systems Business Unit. $\mathrm{He}$ is engaged in research and development on automotive power measurement systems and measurement control technology. In 2016, he received $\mathrm{Ph} . \mathrm{D}$. degree from Hiroshima University. In 2017, he received an IEE Japan Electronics, Information and Systems Society Distinguished Transaction Pa-

per Award.

Masakatsu Nomura (Fellow) received the M.E. degree from Nagoya

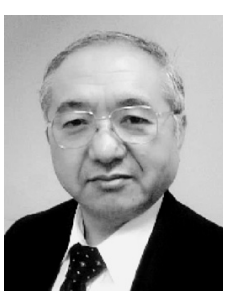
University, Japan, in 1977. In 1977, he joined MEIDENSHA CORPORATION. He currently belongs to the R\&D Group. He is engaged in research and development on power electronics and measurement control technology. In 2009, he received Ph.D. degree from Meiji University. In 1993, he received Ohm Technical Prize. In 2015, he received IEEJ Industry Applications Society Technical Development Award. 